\title{
Assessment of the Degree of Implementation of Industry 4.0 Technologies: Case Study of Murcia Region in Southeast Spain
}

\author{
Antonio Guerrero Gonzalez, Daniel Robles Quinonero, Samuel Fraile Vega
}

\author{
Polytechnic University of Cartagena \\ Doctor Flemming, 30203 Cartagena, Murcia, Spain \\ E-mail.antonio.guerrero@upct.es; daniel.robles@upct.es; samuel.fraile@upct.es
}

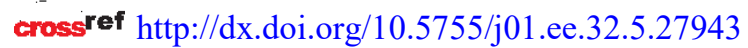

\begin{abstract}
This work analyzes how the so-called Industry 4.0 technologies are being implemented in companies in the Region of Murcia, in Southeastern Spain. The objective was to determine through questionnaires and face-to-face interviews the current state of 4.0 technologies in Murcia, including additional data of the companies, such as age, number of employees and turnover. Most types of companies in the Region were represented in terms of size, age, turnover, profits and profitability. This study analyzes the relationship between the degree of implementation of 4.0 technologies, investment and training of workers, with companies' seniority, number of employees, turnover, profits and profitability. The results obtained are significantly higher in companies with higher turnover, profits and profitability, which in turn, have the best levels of investment and training of their workers in 4.0 technologies. The opinions of the companies determined the factors that drove the companies to implement these technologies, the factors perceived as barriers, the opportunities in the current context that encourage the adoption of technologies, as well as the threats that may jeopardize their progress in digital transformation. The conclusions obtained can be taken into account in regional policies that implement appropriate actions to help drive the fourth industrial revolution in the region.
\end{abstract}

Keywords: Industry 4.0; Implementation of Industry 4.0; Digital Transformation; Maturity Mode; Business Competitiveness.

\section{Introduction}

Industry 4.0, Technologies 4.0, Fourth Industrial Revolution or simply Digital Transformation of Industry have become the paradigm or current of the world economy since the term was coined at the Hannover Fair in 2011. Dr. Klaus Schwab, founder of the World Economic Forum (WEF) argues that this revolution is different in scale, scope and complexity from previous ones and is affecting multiple disciplines, economies, industries and governments (Schwab, 2016). Industry 4.0 as a concept also derives from an initiative of the German government to safeguard the long-term competitiveness of manufacturing industry (Kagermann et al., 2013).

Industry 4.0 is based on integrating cyber-physical systems into industrial manufacturing processes (Lasi et al., 2014) establishing an intelligent, self-regulatory and interconnected value creation (Liao et al., 2017). This fourth industrial revolution focuses its transformative potential on the creation of intelligent machines and factories, on storage systems and on production facilities that can exchange information and data, initiate actions and control themselves autonomously. Its interconnection through the Internet, the so-called Internet of Things (IoT), has generated great technological leaps in engineering, manufacturing, material flow and supply chain management (Ethirajan \& Kandasamy, 2019). The emerging research on Industry 4.0 and its consequences focuses on technological developments related to cyber-physical systems and their organizational implementation (Cimini et al., 2017, Lee et al., 2015, Mosterman \& Zander, 2015). Since Industry 4.0 is a recent concept, academic research on issues related to its past, present and future is relatively new (Kang et al., 2016).
In addition to research in the technical field, current research looks at how Industry 4.0 affects value creation in companies and in industry in general (Kiel et al., 2017). The significant but little studied implications of Industry 4.0 in industrial value chains are examined in Kiel et al. (2017) and Muller et al. (2018). The implementation of Industry 4.0 technologies offer new opportunities for companies in a digitized society such as access to high-quality industrial data to optimize production, a better online business framework, and the promotion of the use of artificial intelligence in companies, among others. The impact of industry 4.0 in modern business environments is discussed in Brunet-Thornton \& Martinez (2018).

The strengthening of the company and industry as well as the commitment to the reindustrialization of sectors of the European economy with digital technologies have numerous and varied benefits for the different layers of society. The small and medium-sized companies are the main focus of attention of the new EU policies and strategies. Taking into account that $99 \%$ of the companies in the EU are SMEs (small and medium-sized companies) and hire between $50 \%$ and $70 \%$ of the full-time equivalent of employees, with a gross added value of more than $50 \%$ of the European economy (Airaksinen et al., 2017), the EU's reindustrialization strategies focus largely on policies to promote the digitization of small and medium-sized companies, as they are the real European business engine. This is something that has already penetrated the EU member states, and the national and regional strategies (smart specialization strategies) have SMEs as the central axis of their policies.

In the current literature, there is still a lack of systematic reviews of the state of the art of this new wave of industrial revolution as regards the special characteristics and 
requirements of Small and Medium-sized Enterprises (SMEs) (Arnold et al., 2016; Matt \& Rauch, 2020). Given that SMEs play an essential role in the creation of industrial value, in Muller \& Voigt (2018) industrial value creation with Industry 4.0 technologies is studied covering economic, ecological and social aspects comparing Chinese and German SME. SMEs have to respond to increasingly complex customer expectations, 4.0 technologies provide tools to support unitary and customized production, in Moeuf et al. (2020) the risks, opportunities and critical success factors are analyzed in relation to SME performance. In turn, to incorporate value creation through smart manufacturing in Mittal et al. (2019) a framework for SMEs that incorporates 4.0 technologies is proposed. Company executives are the driving forces behind the introduction of new technologies and sometimes, the main obstacles to Industry 4.0, in Horvath \& Szabo (2019) a survey-based study is presented that analyzes how this group interprets the concept of Industry 4.0. In Sahi et al. (2020), 204 interviews were conducted in SMEs to determine the effects of strategic orientation on the operational ambidexterity-performance link.

As happened when SMEs adopted information and communication technologies (ICT), the implementation of Industry 4.0 technologies in companies is a pressing and decisive need because it provides competitive advantages to those that introduce them (Aguilar et al., 2009), which means studies are urgently needed to monitor the situation of these technologies and their penetration in companies. However, the academic research in the field of Industry 4.0 mainly focuses on large companies (Radziwon et al., 2014) and not so much on SMEs (Villa \& Taurino, 2019) because SMEs often have significantly lower levels of digitalization and 4.0 technologies. In Muller et al. (2020) the redesign of business models as a response to Industry 4.0 is analyzed and a comparison is made between SME and large enterprises.

In this work, the research is mainly concerned with SMEs, which make up most of the companies in Europe and in the Region of Murcia in Spain, which is the study area. Analyzing the implementation of 4.0 technologies in SMEs helps to create a more reliable image of the impact and organizational implications of the phenomenon of the fourth industrial revolution in this type of company. In order to adequately guide the actions of the regional government to support digitization in companies and the industrial sector, it is, therefore, proposed to create a company digital maturity barometer.

Few company digital maturity analyses of the degree of implementation of 4.0 technologies have been carried out so far (Schmidt et al., 2015). In Schumacher et al. (2016) a new model is proposed to assess the degree of maturity of companies in the domain of discrete manufacturing. Pollak et al. (2020) gives the results of a study on maturity in 4.0 technologies in Polish enterprises and identifies the limitations and challenges that arise within the Industry 4.0 framework. Habanik et al. (2019) analyse the selected indicators of sustainable development and the effects of Industry 4.0 on their development in the Slovak Republic. Kloviene \& Uosyte (2019) review the scientific literature in the Performance Measurement System (PMS) in the context of Industry 4.0.
The Spanish government has designed an advanced open-source digital self-diagnostic tool by which companies can obtain a report on their current level of digital maturity based on 6 defined stages: static, conscious, competent, dynamic, referent and leader (Lazaro, 2017).

This work analyzes the degree of implementation of 4.0 technologies in the Region of Murcia in Southeast Spain with a population of $1,493,898$. This region has a varied business and industrial fabric, being one of the largest fruit, vegetable and flower producing areas in Spain that exports to all of Europe. It has important vineyards in Jumilla, Bullas and Yecla which produce wines with Denomination of Origin. In the northern part of the Region there is an important industrial nucleus focused on the manufacture of furniture and upholstery, with the notable presence of auxiliary companies. The Region also has an important tourist sector. Its industry stands out in the petrochemical and energy sector (mainly in the Escombreras Valley in Cartagena) and the agri-food industry, also very powerful in large areas throughout the Region. Its industrial sector plays a key role in generating wealth (and employment), since industrial economies are more competitive, increase their exports, and are more resistant to adverse economic cycles. Technologies 4.0 make companies more competitive, which is why we want to know the degree of implementation of these technologies in the Region of Murcia, which will be important to undertake actions to strengthen the industrial sector, which has an impact on the stability and economic progress of the region.

The companies in Murcia were monitored to extract the situation of the current state of implementation of industry 4.0 technologies to help regional government to promote the re-industrialization of the socioeconomic fabric of the Region of Murcia by promoting measures in SMEs aimed at detecting and taking advantage of the growth opportunities that Industry 4.0 technologies allow, highlighting the importance of continuous training in digital skills and project-based learning to transform organizations.

The aim of this work is to determine the level of implementation of Industry 4.0 technologies and the state of digital transformation in the Region of Murcia, both from a general point of view, as well as in terms of each of its most relevant technologies. In turn, this work also investigates conditioning factors for the penetration of these technologies such as the size of the company, age, turnover and profit, as well as the sector in which they operate. It analyzes how the implementation of 4.0 technologies is affected by various factors such as the level of training of employees, government aid, as well as the factors that push the implementation of these technologies and the obstacles perceived by entrepreneurs. The method used was based on the design of exploratory research. For data collection, surveys were carried out based on self-assessment questionnaires with questions related to the objective of the research, in addition to face-to-face interviews with company managers, and this information was combined with economic-financial data from the companies interviewed. In order to have a representative sample of the companies in the Region of Murcia, the companies were selected according to age, number of employees, turnover, profits, profitability and sector. The results obtained are analyzed and discussed showing from the information 
obtained the internal strengths, weaknesses and environmental factors that are influencing the level of implementation of 4.0 technologies in the Region of Murcia. From these analyses, recommendations are extracted to promote the implementation of 4.0 technologies and digitalization in the region.

As proposed in Treece (2018), the aim was to contribute to improving the growth of companies and their competitiveness through digital transformation to expand research on the relationship between dynamic capabilities and digitalization.

\section{Materials and Methods}

The study was carried out through self-assessment questionnaires combined with face-to-face interviews. The information obtained was completed with the companies' economic and financial data.

Two self-assessment questionnaires were accessed online on the Google Forms platform. The first and longest questionnaire included questions of both quantitative and qualitative questions with responses rated on a scale from 0 to 10. The second shorter questionnaire contained only questions essential for the analysis of the results. This could be completed in less than 15 minutes and was more successful in its response.

The questionnaires also requested additional information, such as seniority, number of employees and billing. This information was completed with the information from the Iberian Balance Sheet Analysis System (SABI) database, which contains detailed financial information of more than 2.6 million companies in Spain and Portugal.

We carried out a series of face-to-face visits to some of the companies that responded in November and December 2019 and January and February 2020 to assess the degree of implementation of 4.0 technologies by experts in these technologies external to the companies to validate the selfassessment. During these visits, the answers to the HADA Report Questionnaire (Lazaro, 2017) were answered together. This questionnaire is published by the Spanish Ministry of Industry, Tourism and Trade in its Connected Industry 4.0 strategy to assess digital maturity.

The essential questions included in the questionnaires were the following:

RQ1. What is the degree of implementation of transformation solutions to Industry 4.0 in your organization?

RQ2. How do you assess the level of investment of your organization for the development of Industry 4.0 solutions?

RQ3. How important is government aid (tax exemptions, subsidies, subsidized loans, etc.) for your organization to implement Industry 4.0 solutions?

RQ4. What is the current level of training of your employees in each of the processes in relation to the future needs of Industry 4.0?

RQ5. Indicate the degree of implementation in your organization of the following Industry 4.0 solutions: Internet of Things (IoT), Augmented Reality (virtual and mixed), Autonomous and Collaborative Robotic Additive Manufacturing, Cybersecurity, Computing and Cloud, Big Data, Vertical and Horizontal Integration, BIM (Building
Information Modeling), AI (Artificial Intelligence) and Mobile Applications.

RQ6. Of all the 4.0 technologies implemented in your company, indicate which has had the greatest impact on your financial results.

RQ7. What encouraged you to implement 4.0 technologies?

RQ8. Assessment of the difficulties and barriers to the implementation of Industry 4.0 technologies.

One hundred and fifty-five companies participated in the study.

Most of the types of companies in the Region were represented, both by size and by seniority, turnover, profits and profitability. They are described in the following sections, where it can be seen that most fall into the category of SMEs.

Of the 155 surveyed companies from which we obtained the data to be analyzed, 19 were audited on-site, a visit was made to the company and the degree of implementation of the technologies in the company was analyzed in detail by experts in 4.0 technologies.

To characterize the participating companies, we treated the data obtained by categorizing them according to their age, number of employees, turnover, profits and profitability.

In terms of age, we have a fairly balanced sample with $19 \%$ less than one year old, $20 \%$ between 1 and 5 years old, $17 \%$ between 5 and 10 years old, $18 \%$ between 10 and 25 years old and $26 \%$ with more than 25 years of age. The distribution by seniority is well balanced and the companies are of "all ages".

Regarding the number of employees, the vast majority of the sample (around $94 \%$ ) could be defined as SMEs, since $49.5 \%$ had less than 10 employees, $31.68 \%$ between 11 and 50, $12.87 \%$ between 51 and 250 and only $5.94 \%$ with more than 251 employees. It is clear that small and medium-sized companies are the main business engine in this Region, as they are in the rest of Spain.

Regarding the turnover of the surveyed companies, $66.67 \%$ of the companies had a turnover in the preceding year of less than $€ 2$ million, $17.17 \%$ between $€ 2$ and $€ 10$ million, $10 \%$ between $€ 10$ and $€ 50$ million and $6.06 \%$ with more than $€ 50$ million.

Analyzing the benefits of the surveyed companies, $55 \%$ had a net profit of less than $€ 50,000,13 \%$ between $€ 50,000$ and $€ 100,000,17 \%$ between $€ 100,000$ and $€ 500,000$ and $15 \%$ with more than $€ 500,000$.

In terms of profitability, which is one of the best ratios to determine the economic performance of a company, $42 \%$ of the surveyed companies had a profitability of between 0 and $5 \%, 27 \%$ between 5 and $10 \%$ and $31 \%$ higher than $10 \%$.

\section{Results}

Degree of implementation of 4.0 technologies.

The main result of the study on the implementation of Industry 4.0 technologies in companies in the Region of Murcia was the data on the companies' self-diagnosis, calculated as the average of all the responses to RQ1, where 0 means that there is no 4.0 technology implemented and 10 is a very high degree of 4.0 technology implementation (see 
Figure 1). The results indicate an intermediate state of the implementation of these technologies.

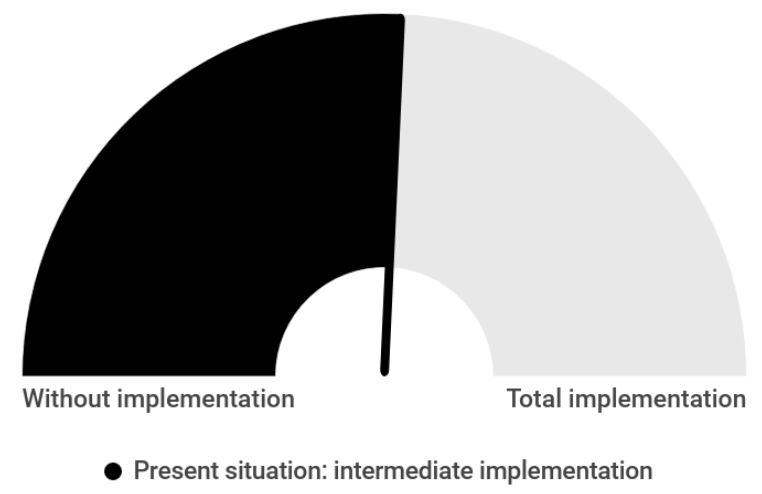

Figure 1. Overall Level of Implementation of Industry 4.0 Technologies

The companies were also asked to assess the degree of implementation of each of the 11 technologies analyzed with question RQ5. The level of implementation of each one can be seen in Figure 2 on a rating scale of 0 to 10 , ( 0 "no implementation" and 10 "high degree of implementation"). Those with the greatest implementation are related to mobile applications (the only one higher than 5), computing and the cloud, and the internet of things (IoT).

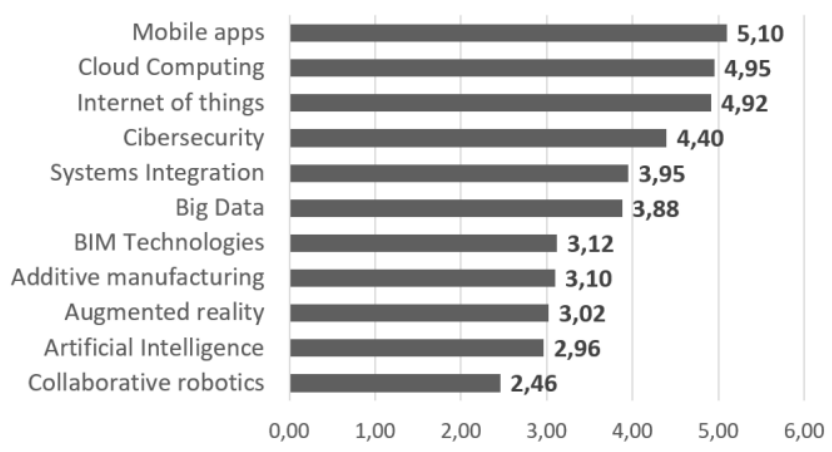

Figure 2. Degree of Implementation of Transformation Solutions Towards Industry 4.0

The least implemented are Building Information Modeling (BIM), additive manufacturing, augmented reality, and both artificial intelligence and everything related to robotics, which do not even reach a score of 3.

The level of implementation of these technologies in the strategy RIS3MUR (Research and Innovation Strategy for Smart Specialisation of Murcia Region) priority areas has been studied for the agri-food, water and environment, logistics and transport, habitat, health, naval, ICT and tourism sectors. Although there are slight differences in the position of each technology for each sector, there is a certain homogeneity in terms of the results. Thus, the technologies with the greatest implementation in the different areas would be mobile applications, computing and cloud, cybersecurity and the internet of things. It is worth highlighting the results obtained in the water sector, with scores above 8 on the scale of 0 to 10 in the technologies mentioned. The interpretation of this data is that in this Region of Murcia,

water is a scarce resource, and water management is highly technologized to meet the demands of the important agrifood industry. In the middle range are technologies related to big data, additive manufacturing, BIM and vertical and horizontal integration. The least implemented technologies in all the sectors are collaborative robotics, artificial intelligence and augmented reality, with values below 3 on the scale of 0 to 10 for most sectors.

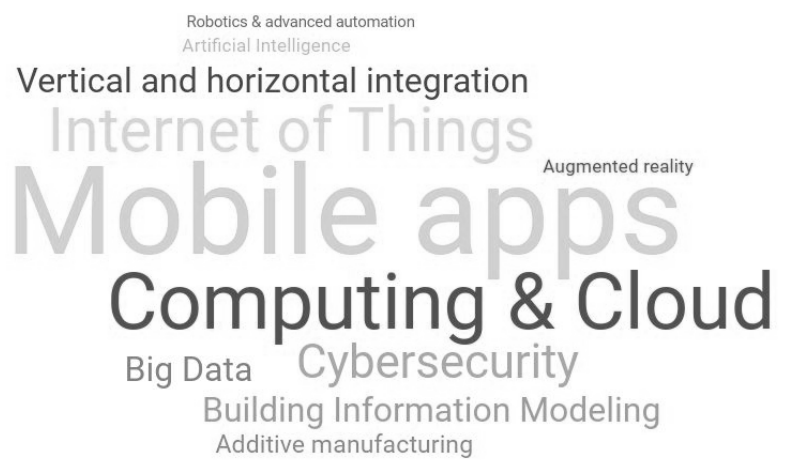

Figure 3. Word Cloud of Transformation Solutions Towards Industry 4.0

Training in 4.0 Technologies

The issues of training and the lack of internal resources and qualified workers in companies are crucial parts of the implementation of industry 4.0 technologies.

According to the self-diagnosis of the companies themselves with RQ4 question, on a scale from 0 to 10 , ( 0 "no training" and 10 "highly trained"), the current state of workers' training does not reach a score of 5 out of 10 (labeled "intermediate/low training" in the graph of Figure 4. This low level of training of human resources is one of the main barriers to the implementation of Industry 4.0 technologies.

In Figure 5 only $15 \%$ of the workers have high qualifications, while almost $30 \%$ are low and slightly more than $55 \%$ have a medium level of training.

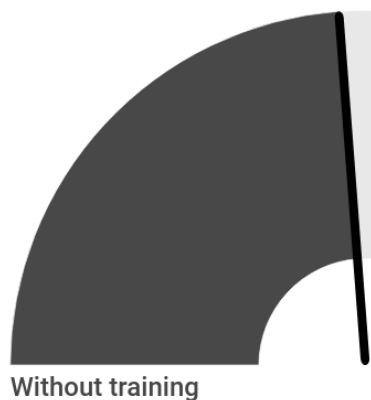

- Present situation: intermediate/low training

Figure 4. Global level of Employees Training Regarding Industry 4.0 Technologies 


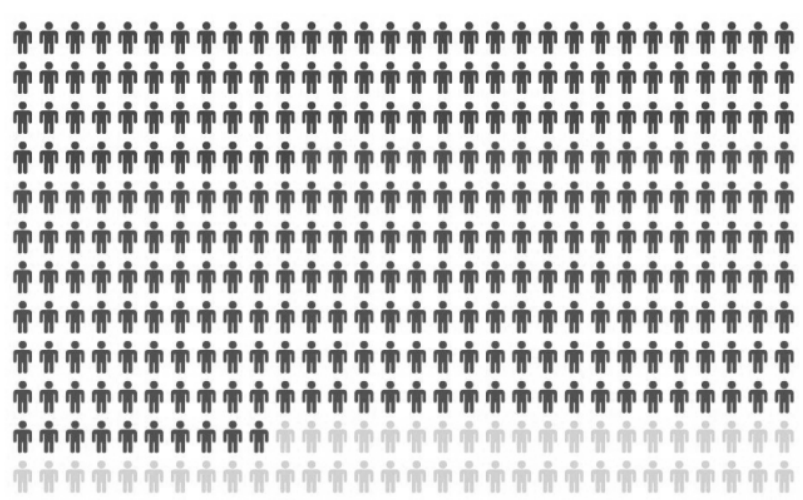

$\bullet$ LOW $\bullet$ MEDIUM $\odot$ HIGH

Figure 5. Levels of Employee Training for Industry 4.0 Technologies

Investments in Technologies 4.0

Regarding the level of investment in industry 4.0 technologies, the companies in the sample answered the selfdiagnosis question RQ2 at a level slightly above the score of 5 , on a scale from 0 to $10,(0$ "no investment" and 10 "total or maximum investment"). The current situation indicates a state of "intermediate investment" as shown in Figure 6.

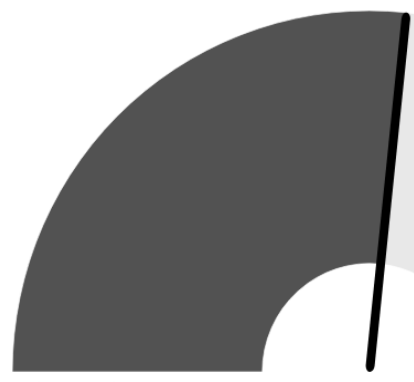

Without investment

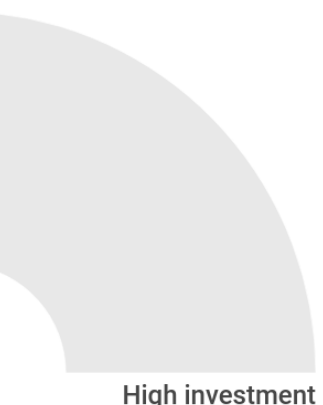

High investment
- Present situation: intermediate investment

Figure 6. Investment in Industry 4.0 Technologies

Implementation, Investments and Training in 4.0 Technologies

Three of the main variables analyzed were the degree of implementation of 4.0 technologies from RQ1, the level of investment for their development and implementation from RQ2 and the level of employee training from RQ4 in relation to number of employees, turnover, profits and profitability obtained from to SABI database. In Figures 7 to 11 the variables are evaluated on a scale of 0 to 10 , although the graphs show a scale of 3 to 8 to better visualize the results.

\section{Results by Seniority}

Regarding the age of the companies, the greatest implantation, in investment and training, is in companies between 1 and 5 years old and all the variables fall as the age of the company increases. In general, the youngest companies are the most willing to implement 4.0 technologies, while those more than 25 years old present the lowest values, see Figure 7.

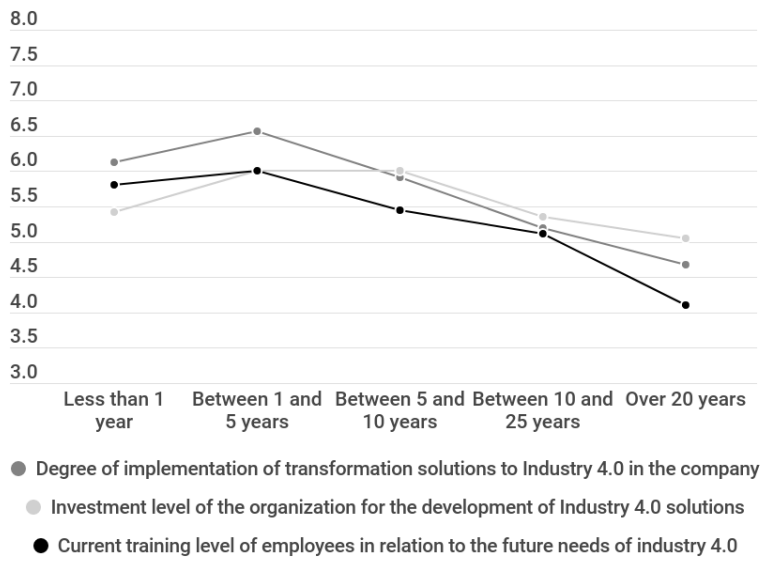

Figure 7. Implementation, Tnvestment and Training Results According to Company Age

\section{Results by Number of Employees}

The variables can be seen to increase as the number of employees increases, with the best results of implementation, investment and training in companies with between 51 and 250 workers, i.e. medium-sized companies. SMEs with up to 250 workers clearly show an upward trend as the number of workers increases.

In the micro-SMEs (less than 10 workers) the results are around 4.5 (on a scale of 1 to 10), while small companies (11 to 50 workers) slightly exceed 5 and reaching values higher than 6 in medium-sized companies (between 51 and 250 workers), as shown in Figure 8. There is a notable increase in the training variable in the largest companies.

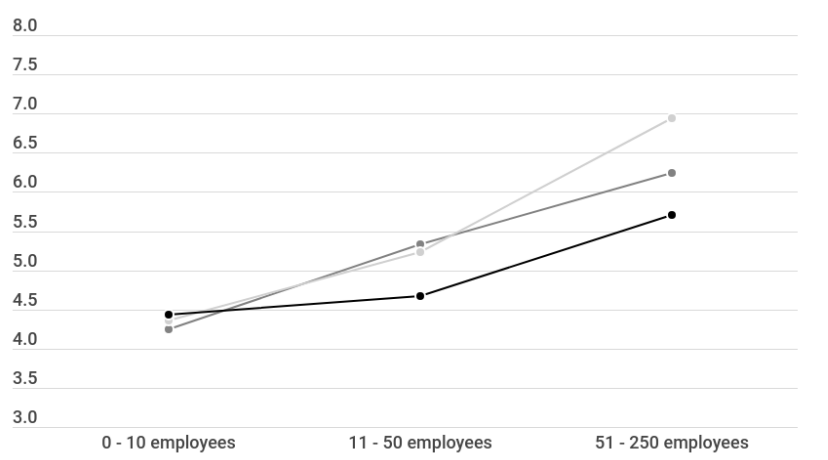

- Degree of implementation of transformation solutions to Industry 4.0 in the company - Investment level of the organization for the development of Industry 4.0 solutions

- Current training level of employees in relation to the future needs of Industry 4.0

Figure 8. Implementation, Investment and Training Results According to the Number of Company Employees

\section{Results by Turnover}

It can be seen in Figure 9 that as turnover increases, the results of implementation, investment and training also increase. As expected, the variable that increases most with turnover is the level of investment in technologies and solutions of Industry 4.0, since, as with profits, the companies with the highest turnovers have higher investment capacities, as can be seen in this graph, where the best results for the three variables are obtained by companies with more than $€ 50$ million annual turnover. 


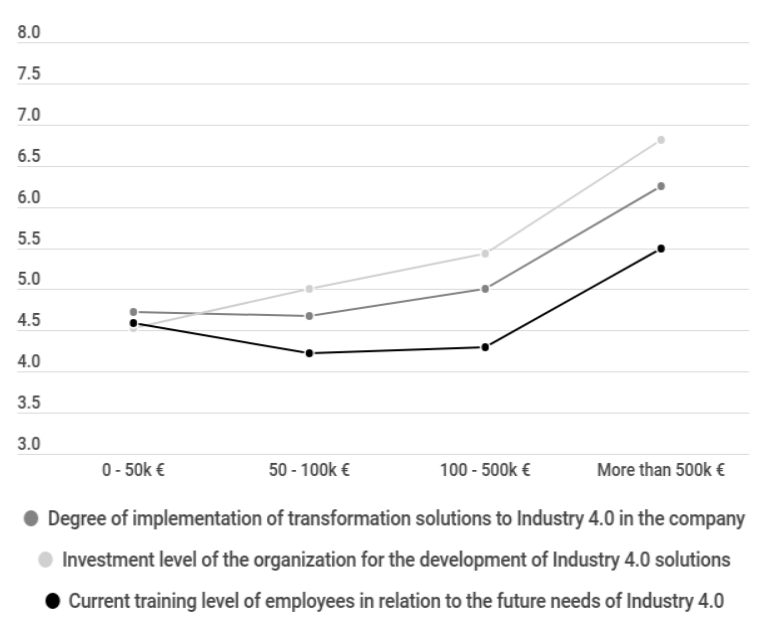

Figure 9: Implementation, Investment and Training Results According to Company Turnover

\section{Results for Profitability.}

With regard to profitability, perhaps the most representative variable of a company's efficiency, we once again see that those with the highest profitability (values above $10 \%$ ) are the ones that most implement investment and training in industry 4.0 technologies.

The curves in Figure 11 show an upward trend as profitability rises, but the companies with more than $5 \%$ profitability show the highest growth, since they are the healthiest companies and are best able to undertake investments. The same thing happens with training, which grows as profitability increases, exceeding the threshold of 5 in companies with higher than $10 \%$ profitability.

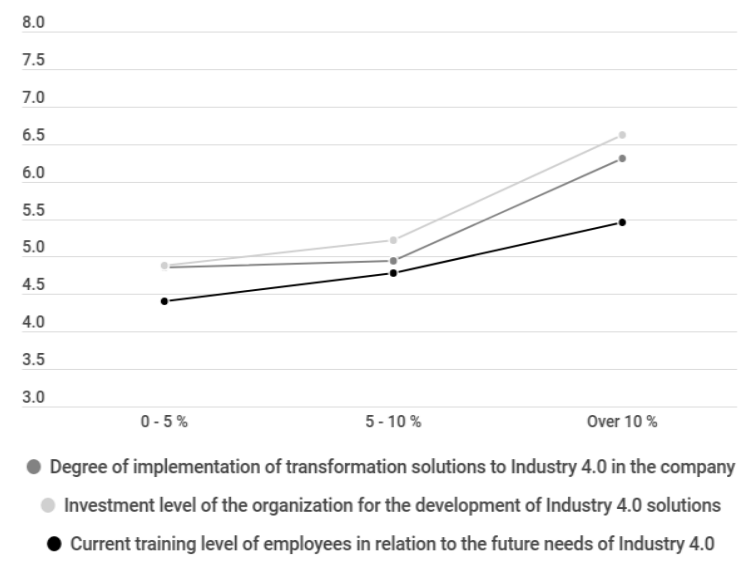

Figure 10. Implementation, Investment and Training Results According to Company Profits

Reasons for the Implementation of 4.0 Technologies in the Company

Of the reasons for implementing 4.0 technologies answered in RQ7, more than $70 \%$ of the responses aimed to increase the efficiency of not only their production systems but also billing and profits, while about $70 \%$ of the companies cited the introduction of new products, services or business models as shown in Figure 12. Around $60 \%$ expressed a desire to position themselves as the leaders in their sector to gain an advantage over competitors. Systems and process efficiency was given as the motivation by just over $50 \%$ of the companies.

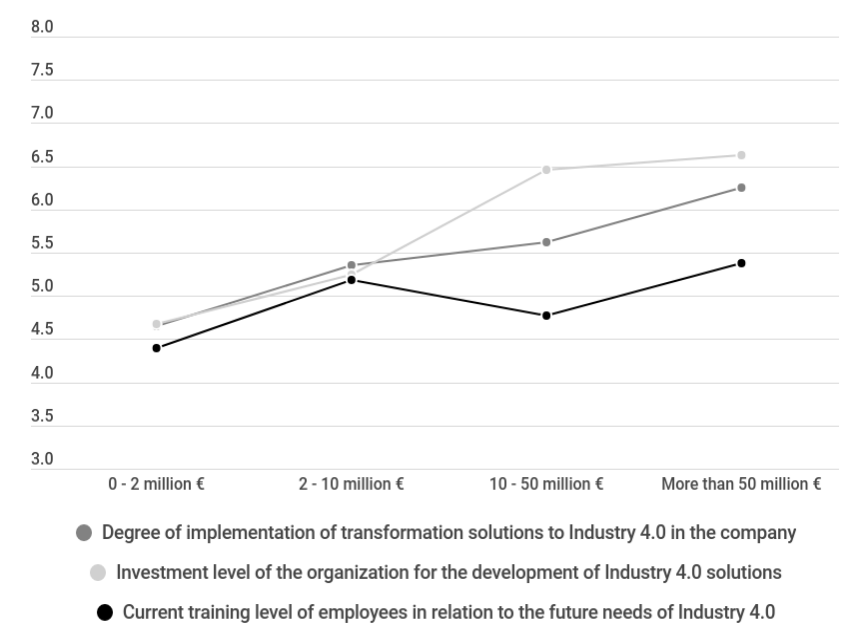

Figure 11. Implementation, Investment and Training Results According to Company Profitability

Surprisingly, only about $30 \%$ of the responses reflected an interest in increasing energy efficiency and reducing energy consumption in their production processes.

Difficulties for the Implementation of 4.0 Technologies

One of the most relevant issues in this study was assessing the barriers and difficulties encountered when implementing new technologies within business organizations, not only to evaluate how they could be overcome but also to help define the appropriate lines of action and policies.

When asked to evaluate the difficulties and barriers involved in question RQ8, more than $65 \%$ reported that the biggest barrier was the lack of financing, while more than $60 \%$ also mentioned the lack of internal resources and qualified workers. This information on training results is closely related to what has already been stated above about the training of company workers in what we could call 4.0 skills.

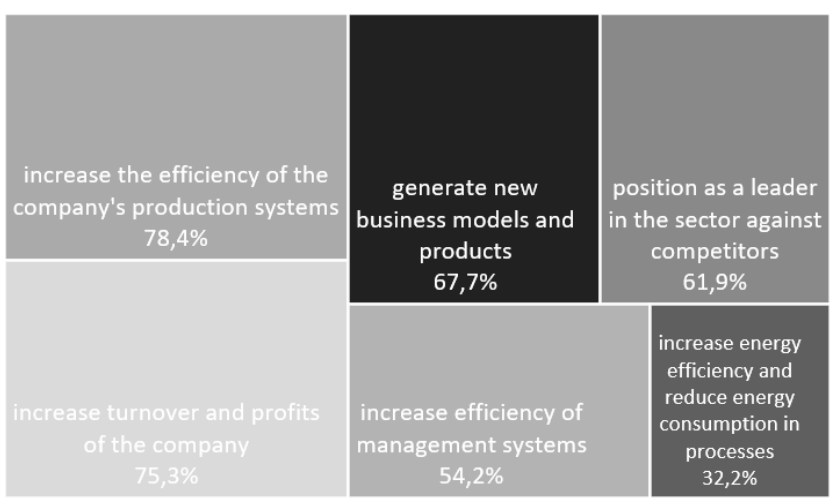

Figure 12. Motivations for the Implementation of Industry 4.0 Technologies 


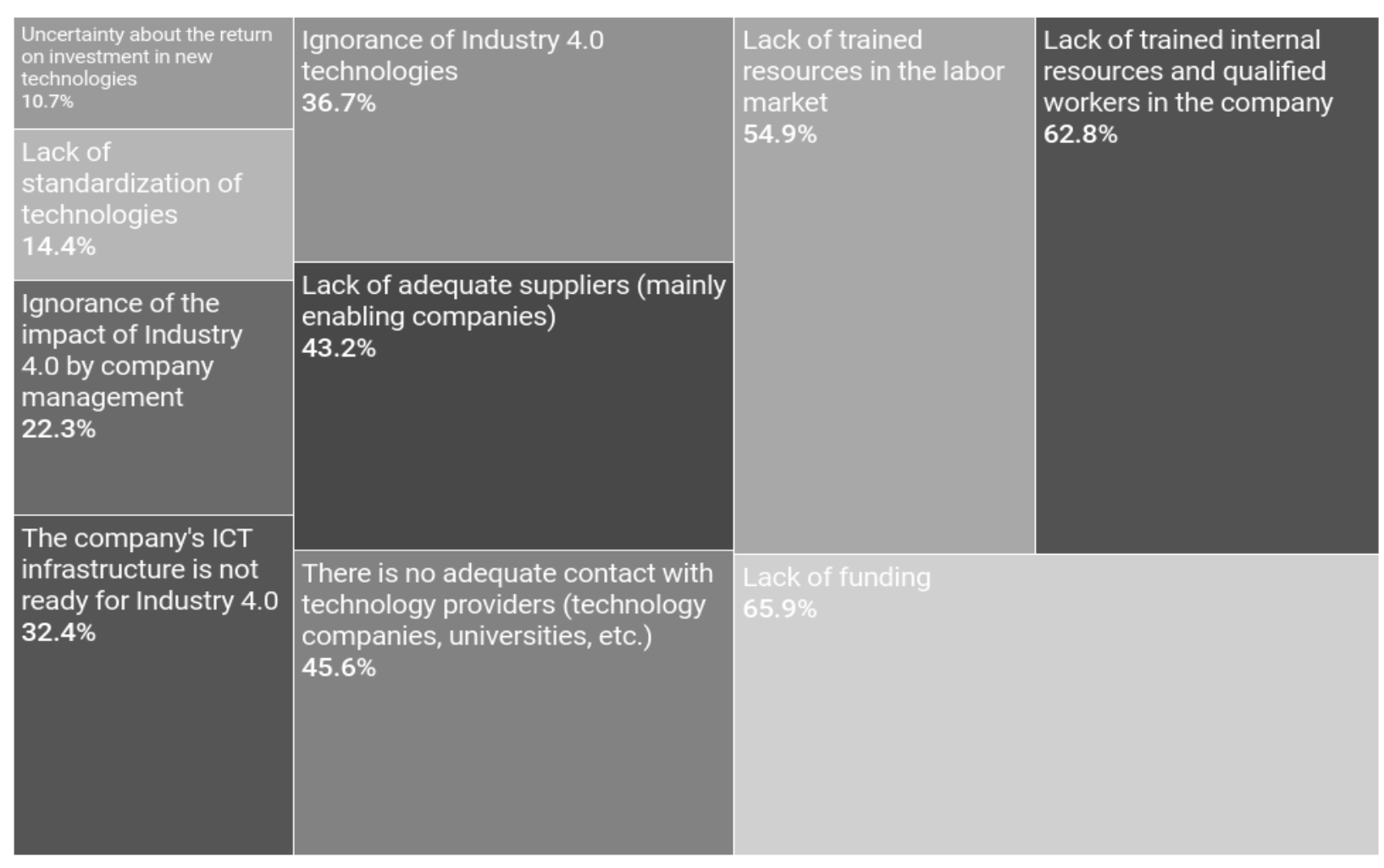

Figure 13. Difficulties and Barriers for the Implementation of Industry 4.0 Technologies in the Firms

Around $40 \%$ of the companies responded to aspects such as the lack of knowledge of Industry 4.0 technologies or the lack of suitable suppliers (enabling companies). They also mentioned the lack of contact with universities or technology companies, which highlights the importance of knowledge transfer and the existing deficiency in publicprivate collaboration.

Other barriers mentioned included an ignorance of 4.0 technologies (around $36 \%$ ) or of their possible impact (around $22 \%$ ). About $30 \%$ stated that their information and communication technology (ICT) infrastructure was not ready for their implementation. About $15 \%$ indicated the barrier of the lack of standardization of 4.0 technologies and only around $10 \%$ cited the uncertainty of the financial return on investing in new technologies.

\section{Discussion}

The results obtained from this analysis give us a glimpse of the internal strengths, weaknesses and environmental factors that are influencing the level of implementation of 4.0 technologies in the Region of Murcia. The former refers to factors such as organization, $R \& D$ potential, innovation, marketing, finance and production, while the external aspects include circumstances or trends beyond the control of the companies, such as political, social, economic or technological factors.

One of the factors driving the progress and improvement of 4.0 technologies implementation levels in industry is the favorable perception by the companies themselves of the benefits of their use of these technologies, which was extracted from the answers to RQ7; this positive perception of 4.0 technologies is also observed in a similar study conducted in Pollak et al. (2020) in the Upper Silesia region (Poland). They mostly consider that 4.0 technologies will improve the efficiency of production systems $(78.4 \%)$, generate new business $(67.7 \%)$, increase the return and profits $(75.3 \%)$, and all this will allow them to have a better position in relation to their competitors $(61.9 \%)$. All this is reflected in Figure 12, where the main motivations for the integration of these technologies in companies are collected. In addition to this, there is a good current level of ICT infrastructure in the Region of Murcia (only $32.4 \%$ answered that ICT infrastructure is not ready for 4.0 technologies), there is a wide use of cloud services, as well as a good current level of innovation in large companies, which provide a good basis for the implementation of 4.0 technologies.

On the other hand, companies perceive several factors that slow down the incorporation of 4.0 technologies in companies, obtained in response to RQ8. One of the most important is that a significant investment is required to carry out a comprehensive transformation plan in the company with 4.0 technologies, this barrier factor is also detected in Vuksanovic et al. (2020) and Pollak et al. (2020). Moreover, this transformation plan is accompanied by the need to hire qualified personnel and the lack of training of their own employees in these technologies $(62.8 \%)$ and external suppliers $(54.9 \%)$. Added to this is the fact that some sectors benefit more than others from enabling technologies, so this transformation plan must be carefully designed for each case. In addition, companies will have to develop and implement strategies to protect themselves from cyberattacks (Shi et al., 2019), as digitization exposes the company to this type of threat and this represents an additional cost to be taken into account. In the case of 
SMEs, they usually have little contact with universities, Public Research Organizations and Technology Centers, which also hinders progress in the incorporation of these technologies.

There are several opportunity factors for companies in the Region of Murcia that encourage them to introduce 4.0 technologies. There is significant regional support for investments to incorporate enabling technologies. In addition, there is an important ecosystem of digital enablers to help the transformation of companies to Industry 4.0. Rapid technological evolution is opening new markets for products and services incorporating these technologies. Industry 4.0 has the capacity to completely remake relationships with customers, employees, and market (Vuksanovic et al., 2020; McDonald \& Rowsell, 2012). On the other hand, SMEs in new supply chains find fewer entry barriers to participate in new markets. In addition, companies have the possibility of having tax reductions for R\&D\&I when they innovate their processes and products.

There are several threats that slow down the level of implementation of 4.0 technologies. On the one hand, there is the shortage of specialists in enabling technologies. In Vuksanovic et al. (2020) this same problem is detected in the Serbian manufacturing sector. Innovation cycles are much faster than those of education, which creates imbalances between formal training and the need for knowledge in current technology, which can generate a lack of specialists in enabling technologies, this is a problem also detected in Pollak et al. (2020). There are companies, especially the smaller ones that lack an innovative attitude, which affects the progress in the implementation of new technologies. It is necessary to have a dynamic updated catalog of digital enablers in the region and for it to be accessible to companies that need their services for the implementation of technologies. In addition, the current economic instability due to the COVID-19 epidemic hinders investment in R\&D\&I.

From the results obtained, it can be seen that the greatest implementation of 4.0 technologies, investment and worker training is in companies between 1 and 5 years old, mediumsized (between 50 and 249 workers), and those with the highest turnover, profits and profitability, i.e. those with the best financial results (which does not necessarily mean that there is a correlation between these and the implementation of 4.0 technologies, since this correlation does not imply a causal relationship).

\section{Conclusions}

Although companies are increasingly aware of the need to adopt Industry 4.0 technologies to be more competitive, and there are differences in the methods used and investments made, the results obtained from this study indicate that the level of implementation of 4.0 technologies in the Region of Murcia is medium. To promote the implementation of 4.0 technologies and digitization, the barriers and threats perceived by the company must be mitigated. These have been identified in this study as the need for investment and lack of funding, training of workers and access to external services of digital enablers. Based on the results, it is considered that it is key to facilitate investment in capital goods, technical training of workers and the hiring of qualified personnel, as well as the identification of third parties that can help or directly implement different initiatives, for example, Technological-Based Companies (TBC) specialized in certain technologies, universities, public research organizations, or technology partners. These measures would improve the implementation of initiatives aimed at implementing technologies in companies, similar measures are proposed in Vuksanovic et al. (2020) for the Serbian manufacturing sector.

Strategic planning is of vital importance to undertake projects aimed at transforming companies through a culture aligned and adapted to individual strategies, which must be understood by all areas of the organization as a driver for improving efficiency and effectiveness, for example, extending this attitude through an open work environment to promote values such as innovation, change or learning.

Closely linked to increasing digitization, advanced automation of processes is also taking place, as more and more companies are aware of the need to automate as much as possible. These processes are linked to possible reluctance in some sectors, mainly among workers, who see in the idea that "machines don't make people sick" a challenge to production processes in which people may end up being replaced by robots. In Vuksanovic et al. (2020), companies in Serbia consider resources rather as an obstacle to the implementation of Industry 4.0 when they lack the competencies and skills. In this regard, it is necessary to understand that industrial revolutions always entail changes and that greater automation does not necessarily entail the loss of jobs; on the contrary, new jobs will be created linked to these transformations, for which qualified professionals trained in the use and handling of these technologies will be needed (Milford \& Reston, 2017; Winick, 2018). For this it is important to contemplate the training aspects of the company's own personnel in the digital transformation strategy.

To make it easier for companies to identify third parties that can intervene in digital transformation processes an ecosystem must be created to give visibility to these third parties to provide access to the actors that would make the digitization of companies possible. Although Industry 4.0 is generally considered an opportunity, it is necessary to access the levers to trigger this change. A "Digital Hub" with visible digital enablers is needed to increase collaboration with third parties, which would have a direct impact on investments and improve the competitiveness of companies in the region.

It is essential to promote collaboration between companies and other institutions such as universities and research centers to improve the transfer of research results to the productive and business fabric. A cooperative ecosystem is needed in which companies undertake projects to improve and increase their competitiveness with researchers in a cooperation that transcends the traditional university-business approach.

As this report was completed in July 2020, we have already glimpsed some of the consequences of the Covid19 health crisis. Although the data were collected in late 2019 and early 2020, we cannot fail to mention its significant impact on the business fabric and the economy 
in general. One of the main consequences that can already be glimpsed is that technology is presented as an ally for a joint response leading to the fastest way out of the crisis. During the confinement in Spain between March and June 2020, digitalization processes accelerated dramatically, bringing about major changes and advances in the way companies work. These changes, which are here to stay, should be seen as an opportunity to modernize and improve competitiveness.

\section{Acknowledgement}

This research has been supported by the Instituto de Fomento de la Region de Murcia within the Observatory 4.0 of Murcia Region.

\section{References}

Aguilar, A. S., Seaton, C. E., Gonzalez Ladron de Guevara, F., \& Torralba, J. M. (2009). Integracion de recursos de tecnologias de informacion y comunicaciones en el negocio electronico de pequenas y medianas empresas. Puente Revista Cientifica, 3(1), 57-68.

Airaksinen, A., Luomaranta, H., Alajaasko, P., \& Roodhuijzen, A. (2018). Statistics on Small and Medium-sized Enterprises: Dependent and Independent SMEs and Large Enterprises. Eurostat statistic explained. Available from internet: https://ec.europa.eu/eurostat/statistics-explained/index.php?title=Statistics_on_small_and_medium-sized_enterprises

Arnold, C., Kiel, D., \& Voigt, K. I. (2016). How the Industrial Internet of Things changes business models in different manufacturing industries. International Journal of Innovation Management, 20 (8), 1640015-1-1640015-25. https://doi.org/10.1142/S1363919616400156

Brunet-Thornton, R., \& Martinez F. (2018). Analyzing the Impacts of Industry 4.0 in Modern Business Environments. Hersey PA: IGI Global. https://doi.org/10.4018/978-1-5225-3468-6

Cimini, C., Pinto, R., \& Cavalieri, S. (2017). The business transformation towards smart manufacturing: a literature overview about reference models and research agenda. IFAC paper online, 50(1), 14952-14957. https://doi.org/10. 1016/j.ifacol.2017.08.2548

Ethirajan, M., \& Kandasamy, J. (2019). A review of Internet of Things (IoT) embedded sustainable supply chain for industry 4.0 requirements. Computer \& Industrial Engineering , 127, 925-953. https://doi.org/10.1016/ j.cie.2018.11.030

Habanik, J., Grencikova, A., \& Krajcomm K. (2019). The Impact of New Technology on Sustainable Development. Inzinerine Ekonomika-Engineering Economics, 30(1), 41-49. https://doi.org/10.5755/j01.ee.30.1.20776

Horvath, D., \& Szabo, R. Z. (2019). Driving forces and barriers of Industry 4.0: Do multinational and small and mediumsized companies have equal opportunities?. Technological Forecasting and Social Change, 146, $119-132$. https://doi.org/10.1016/j.techfore.2019.05.021

Kagermann, H., Wolfgang, W., \& Helbig, J. (2013). Securing future of German manufacturing industry Recommendations for implementing the strategic initiative INDUSTRIE 4.0. Frankfurt: Acatech-National Academy of Science and Engineering.

Kang, H. S., Lee, J. Y., Choi, S., Hyun, K., Park, J. H., Son, J. Y., Kim, D. H., \& Noh, S. D. (2016). Smart manufacturing: Past research, present findings, and future directions. International Journal of Precision Engineering and Manufacturing-Green Technology, 3, 111-128. https://doi.org/10.1007/s40684-016-0015-5

Kiel, D., Arnold, C., Muller, J., \& Voigt, K. I. (2017). Sustainable Industrial Value Creation: Benefits and Challenges of Industry 4.0. International Journal of Innovation Management, 21, 1740015, 1-34. https://doi.org/10.1142/ S1363919617400151

Kloviene, L., \& Uosyte, I. (2019). Development of Performance Measurement System in the Context of Industry 4.0: a Case Study. Inzinerine Ekonomika-Engineering Economics, 30(4), 472-482. https://doi.org/10.5755/ j01.ee.30.4.21728

Lasi, H., Fettke, P., Feld, T., \& Hoffmann, M. (2014). Industry 4.0. Business \& Information Systems Engineering, 6(4), 239-242. https://doi.org/10.1007/s12599-014-0334-4

Lazaro, O. (2017). Analysis of National Initiatives for Digitising Industry. Spain: Industria Conectada 4.0. European Commission. Available from internet: https://ec.europa.eu/futurium/en/system/files/ged/es_country_analysis.pdf

Lee, J., Bagheri, B., \& Kao, H.A. (2015). A Cyber-Physical Systems architecture for Industry 4.0-based manufacturing systems. Manufacturing Letters, 3, 18-23. https://doi.org/10.1016/j.mfglet.2014.12.001

Liao, Y., Deschamps, F., de Freitas Rocha Loures, E., \& Pierin Ramos L.F. (2017). Past, present and future of Industry 4.0 - a systematic literature review and research agenda proposal. International Journal of Production Research, 55(12), 3609-3629. https://doi.org/10.1080/00207543.2017.1308576

Matt, D. T., \& Rauch, E. (2020). SME 4.0: The Role of Small- and Medium-Sized Enterprises in the Digital Transformation. In Matt D., et al. (Ed.), Industry 4.0 for SMEs, (pp. 3-36). Cham: Palgrave Macmillan. https://doi.org/10.1007/978-3-030-25425-4_1 
McDonald, M. P., \& Rowsell-Jones, A. (2012). The Digital Age: Exploiting Information \& Technology for Business Advantage. Stamford, CT, USA: Gartner Inc.

Milford, M. A., \& Reston, V. A. (2017). Cyber Security Skills Crisis Causing Rapidly Widening Business Problem. Information Systems Security Association. Available from internet: https://www.members.issa.org/page/2017_issaesg_surv

Mittal, S., Khan, M. A., Purohit, J. K., Menon, K., Romero, D., \& Wuest, T. (2019). A smart manufacturing adoption framework for SMEs. International Journal of Production Research, 58(5), 1555-1573. https://doi.org/10.1080/ 00207543.2019 .1661540

Moeuf, A., Lamouri, S., Pellerin, R., Tamayo-Giraldo, S., Tobon-Valencia, E., \& Eburdy, R. (2020). Identification of critical success factors, risks and opportunities of Industry 4.0 in SMEs. International Journal of Production Research, 58(5), 1384-1400. https://doi.org/10.1080/00207543.2019.1636323

Mosterman, P. J., \& Zander, J. (2015). Industry 4.0 as a Cyber-Physical System study. Software \& Systems Modelling,15, 17-29. https://doi.org/10.1007/s10270-015-0493-x

Muller, J. M., Buliga, O., \& Voigt, K. I. (2018). Fortune favors the prepared: How SMEs approach business model innovations in Industry 4.0. Technological Forecasting and Social Change, 132, 2-17. https://doi.org/10.1016/ j.techfore.2017.12.019

Muller, J. M., Buliga, O., \& Voigt, K. I. (2020). The role of absorptive capacity and innovation strategy in the design of industry 4.0 business Models-A comparison between SMEs and large enterprises. European Management Journal, 39(3), 333-343. https://doi.org/10.1016/j.emj.2020.01.002

Muller, J. M., \& Voigt, K. I. (2018). Sustainable Industrial Value Creation in SMEs: A Comparison between Industry 4.0 and Made in China 2025. International Journal of Precision Engineering and Manufacturing-Green Technology, 5(5), 659-670. https://doi.org/10.1007/s40684-018-0056-z

Pollak, A., Hilarowicz, A., Walczak, M., \& Gasiorek, D. (2020). A Framework of Action for Implementation of Industry 4.0. an Empirically Based Research. Sustainability, 12, 5789. https://doi.org/10.3390/su12145789

Radziwon, A., Bilberg, A., Bogers, M., \& Madsen, E. (2014). The Smart Factory: Exploring Adaptive and Flexible Manufacturing Solutions. Procedia Engineering, 69, 1184-1190. https://doi.org/10.1016/j.proeng.2014.03.108

Sahi, G. K., Gupta, M. C., \& Cheng, T. C. E. (2020). The effects of strategic orientation on operational ambidexterity: a study of Indian SMEs in the industry 4.0 era. International Journal of Production Economics, 220, 107395. https://doi.org/10.1016/j.ijpe.2019.05.014

Schmidt, R., Mohring, M., Harting, R. C., Reichstein, C., Neumaier, P., \& Jozinovic, P. (2015). Industry 4.0-potentials for creating smart products: Empirical research results. In Abramowicz, W. (Ed.), Lecture Notes in Business Information Processing, (pp. 16-27). Cham, Switzerland: Springer. https://doi.org/10.1007/978-3-319-19027-3_2

Schumacher, A., Selim, E., \& Wilfried, S. (2016). A Maturity Model for Assessing Industry 4.0 Readiness and Maturity of Manufacturing Enterprises. Procedia CIRP, 52, 161-166. https://doi.org/10.1016/j.procir.2016.07.040

Schwab, K. (2016). The Fourth Industrial Revolution. Cologny/Geneva-Switzerland: World Economic Forum.

Shi, L., Chen, X., Wen, S., \& Xiang, Y. (2019). Main enabling technologies in industry 4.0 and cybersecurity threats. In J. Vaidya, X. Zhang, \& J. Li (Eds.), Cyberspace Safety and Security: 11th International Symposium, CSS 2019 Guangzhou, China, December 1-3, 2019 Proceedings, Part II (pp. 588-597). (Lecture Notes in Computer Science; Vol. 11983 ). Springer. https://doi.org/10.1007/978-3-030-37352-8_53

Teece, D. J. (2018). Business models and dynamic capabilities. Long Range Planning, 51, 40-49. https://doi.org/10.10 16/j.1rp.2017.06.007

Villa, A., \& Taurino, T. (2019). SME Innovation and Development in the Context of Industry 4.0. Procedia Manufacturing, 39, 1415-1420. https://doi.org/10.1016/j.promfg.2020.01.311

Vuksanovic Herceg, I., Kuc, V., Mijuskovic, V. M., \& Herceg, T. (2020). Challenges and Driving Forces for Industry 4.0 Implementation. Sustainability, 12(10), 4208. https://doi.org/10.3390/su12104208

Winick, E. (2018). Cyber-skills shortage means students are being recruited to fight off hackers. MIT Technology Review. Available from internet: https://www.technologyreview.com/2018/10/18/139708/a-cyber-skills-shortage-meansstudents-are-being-recruited-to-fight-off-hackers/

\section{Authors' Biographies}

Antonio Guerrero Gonzalez, $\mathrm{PhD}$ in Industrial Technologies with mention of European doctor by the Polytechnic University of Cartagena (2001), associate professor in the department of Systems Engineering and Automation. Coordinator of the Master of Industry 4.0 of the Polytechnic University of Cartagena. Director of the 4.0 Observatory of the Murcia Region. Specialist in Advanced Automation, Industrial Systems Engineering and Industry 4.0 Technologies, Autonomous Marine Robotics, lines of research and development on which he has directed multiple research projects. 
Daniel Robles Quinonero holds a Bachelor of Architectural Technology and Construction Management by the Technical University of Madrid (UPM) and a Master of Business Administration by the Technical University of Cartagena (UPCT). Daniel works as a Research Management Technician at the Research \& Tech Transfer Unit of the Technical University of Cartagena (UPCT). He is also involved in the European University of Technology (EuT+) project, one of the selected transnational alliances of the European Universities initiative to improve European higher education and research.

Samuel Fraile Vega holds a degree in Administration and Business Management by UCAM (Universidad Catolica San Antonio de Murcia) and a Master of Business Administration by INESEM. Samuel has been working more than five years as a Research Management Technician at the Research \& Tech Transfer Unit of the Technical University of Cartagena (UPCT).

The article has been reviewed.

Received in October 2020; accepted in December 2021.

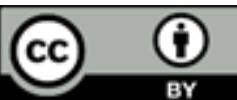

This article is an Open Access article distributed under the terms and conditions of the Creative Commons Attribution 4.0 (CC BY 4.0) License (http://creativecommons.org/licenses/by/4.0/). 